\title{
Who's Eating the Flowers of a Rare Western Nevada Range
} Plant?

\section{By William S. Longland, Melany Aten, Maryke Swartz, and Sarah Kulpa}

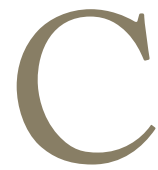

hurchill Narrows buckwheat (Eriogonum diatomaceum; Fig. 1) is a relatively "new" range plant, having been first discovered and recognized as a species in 1997. The species is endemic to a few square miles on the northeastern flanks of the Pine Nut Mountains in Lyon County, Nevada, where it is restricted to approximately 15 disjunct outcroppings of diatomaceous soils formed from sedimentary rock of hard-shelled algae known as diatoms. ${ }^{1,2} \mathrm{~A}$ very recent report ${ }^{3}$ of another possible population on a diatomaceous outcropping in a second mountain range 25 miles away has been made. The association with these conspicuous, chalky-white diatomaceous soil patches is reflected in the plant's Latin name. Because of its restricted distribution and an estimated total population of fewer than 50,000 plants, Churchill Narrows buckwheat is listed as a "sensitive plant" by the State of Nevada, which is working with the Bureau of Land Management (BLM) to try to avoid the need for federal protection status. ${ }^{2}$ As a result, the BLM's Carson City Field Office has initiated a long-term monitoring effort focused on Churchill Narrows buckwheat.

Monitoring during the summer of 2006 indicated that an unidentified animal was clipping and probably consuming many of the flowers produced by the buckwheat plants. Furthermore, there has been no evidence of recent production of new seedlings. This should not sound an immediate alarm, as it is typical for a long-lived desert perennial to experience long delays, perhaps decades, between episodes of seedling recruitment. However, removal of flowers before seeds mature may also partly account for the lack of seedlings. At the very least, this may become problematic when a year finally does occur with appropriate conditions for seedling establishment. Consequently, we set out during summer 2007 to identify which animal(s) remove flowers of Churchill Narrows buckwheat.

\section{Initial Observations}

We began regular visits to several of the sites harboring Churchill Narrows buckwheat in mid-July 2007. The plant is reported to have a wide window for timing of flowering (June-September); ${ }^{1}$ a few plants $(<5 \%)$ had several mature (red, dry) flowers in July, but most were just beginning to bud out with developing (creamy white) flowers, and some continued to produce new buds into early October. Some plants already showed clear evidence of flower heads having been clipped from stalks when we arrived in July, but most flowers were still intact at this time.

Diatomaceous soils are quite soft, almost spongy in some spots, so large animals leave clear footprints when walking through them. We could still find some of our footprints in October at sites we had last visited in July or early August. Thus, it was immediately obvious that flower removal was not due to livestock or other large herbivores, as hoof prints were not evident on any diatomaceous outcroppings. Further visual inspection revealed signs of two types of culprits potentially responsible for removal of Churchill Narrows buckwheat flowers, because rodent burrows and rabbit droppings were evident at all sites we visited. Although either of these animals would have the same general motivation for removing flowers (i.e., food), their specific motives may differ. Rabbits are herbivores, and would therefore consume flowers directly. By contrast, most rodent species in xeric desert habitats of the southwestern United States are granivorous (i.e., seed-eating) mice, pocket mice, or kangaroo rats, and would clip flowers mainly to get access to mature seeds within. Because we did not often find remains of flowers near clipped stalks, we suspected an herbivore would be more likely than a granivore to be our primary candidate. However, it is possible that most clipped flowers had simply blown away before we found them rather than having been consumed. Moreover, some desert rodents (e.g., ground squirrels and some mice) are at least partially herbivorous, so we wanted to determine which species co-occurred with Churchill Narrows buckwheat.

Small Mammal Trapping

We conducted mark-release live trapping for three nights (24-27 July 2007) to determine the species of small 


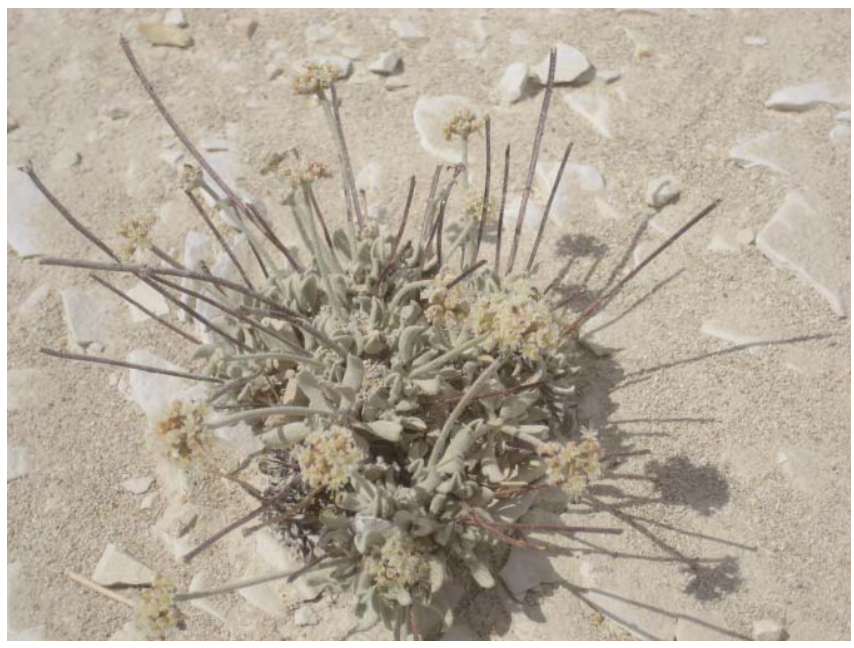

Figure 1. Flowering Churchill Narrows buckwheat (Eriogonum diatomaceum).

mammals present on two diatomaceous soil outcroppings in the Churchill Narrows area. At each of the two trapping sites, we used Sherman ${ }^{\circledR}$ traps baited with bird seed mix in a $5 \times 10$ grid pattern with 10 -m (33-foot) spacing between adjacent trap stations. Thus, there were 50 traps at each of the two sites. Traps were opened each evening and checked the following morning. Captured animals were identified by species and fitted with a numbered ear tag for individual identification.

A single rodent species, the longtail pocket mouse (Chaetodipus formosus), accounted for the vast majority of trap captures. On one of the diatomaceous outcropping sites that we trapped, 21 of 22 animals captured (95.5\%) were longtail pocket mice. At the second site, this species represented 16 of 17 captures (94.1\%). The only other animals captured were a single Great Basin kangaroo rat (Dipodomys microps) at one site and a single whitetail antelope ground squirrel (Ammospermophilus leucurus) at the other site. The numerically dominant pocket mouse and the kangaroo rat have largely (some would claim completely) granivorous diets. The ground squirrel is better characterized as an omnivore, and its diet probably includes a considerable amount of plant material other than just seeds in its diet. However, white-tailed antelope ground squirrels appeared to be uncommon in the Churchill Narrows area; only one individual was captured over 300 trapping nights, and we never saw any of these ground squirrels during our work, despite the fact that this species is quite conspicuous and is the only diurnally (i.e., daylight) active rodent species in the area. From our trapping efforts, we concluded that Great Basin pocket mice were likely candidates for clipping flowers to get to mature seeds. However, if flowers were being removed and directly consumed by an herbivore, as we suspected, a larger, non-rodent species (such as a rabbit) was the likely candidate.

\section{Tracking Stations}

On 31 July 2007, we used a fine-mesh soil sieve to sift powderized soil around 10 randomly chosen Churchill Narrows buckwheat plants on each of two diatomaceous outcropping sites. The fine, sifted soil extended $0.5 \mathrm{~m}$ (1.6 feet) around buckwheat plants, allowing us to read animal tracks within a 1-m-diameter tracking station centered on each plant. We identified tracks left behind for the next two days (1-2 August 2007).

At one of the tracking sites, we found rabbit tracks at 3 of 10 stations, kangaroo rat tracks at one station, and fox tracks at one station. At the second site, we found rabbit tracks at four stations, pocket mouse tracks at five stations, and kangaroo rat tracks at four stations (some stations had tracks of more than one species). We noticed that rodent tracks were not necessarily near or oriented toward the buckwheat plant in the center of the station, whereas rabbit tracks tended to be oriented toward the plant. At least two rabbit species occur in the study area: the blacktail jackrabbit (Lepus californicus, actually a hare rather than a true rabbit) and one or two cottontail rabbit species (the mountain cottontail, Sylvilagus nuttalli, and/or the desert cottontail, S. auduboni). Based on both the open desert habitat and on fairly frequent sightings, we suspected that jackrabbits were probably the species leaving tracks at our stations, but we have seen cottontails in a small canyon nearby that drains an ephemeral creek.

\section{Pellet Counts}

A small number of plant species other than the endemic buckwheat occur on the diatomaceous outcroppings in the Churchill Narrows area, the most common being shadscale (Atriplex confertifolia) and prince's plume (Stanleya pinnata). We counted the number of rabbit droppings ("pellets") within $0.5-\mathrm{m}$ - (1.6-foot)-diameter sampling frames centered on 100 randomly chosen Churchill Narrows buckwheat plants and did the same for the nearest neighbor plants (either shadscale or prince's plume) within $2 \mathrm{~m}$ (6.6 feet) of each of the buckwheat plants on the same diatomaceous outcroppings where we placed tracking stations. Pellet counts have been used previously as an index of the degree to which rabbits use a particular location. ${ }^{4}$ We compared number of rabbit pellets around each buckwheat plant with the number around each paired plant of another species to see if rabbits seemed to concentrate their activities specifically near buckwheat. Many paired pellet counts were omitted from our subsequent analysis, either because nearest neighbor plants were separated by more than $2 \mathrm{~m}$ (6.6 feet), because plants of more than one species fell into the area of the sampling frame, or because there were no rabbit pellets within the sampling frame for both plants in a pair (i.e., we only used counts for which at least one plant in a pair had one or more rabbit pellets). This resulted in 53 paired counts of rabbit pellets around Churchill Narrows buckwheat plants that were compared with counts around neighboring plants 
of a different plant species. The mean $( \pm \mathrm{SE})$ number of rabbit pellets around buckwheat versus neighboring plants was $4.98( \pm 0.73)$ and $3.38( \pm 0.53)$, respectively, which is a significant difference based on a $t$-test for paired comparisons $(t=2.01, d f=51, P<0.05)$. This suggested that rabbit activity on the diatomaceous outcroppings was focused near Churchill Narrows buckwheat more than near other plants in the area.

\section{Camera Traps}

The "smoking gun" in identifying rabbits as consumers of Churchill Narrows buckwheat flowers came from our deployment of two Trailmaster ${ }^{\circledR}$ camera systems at each of two diatomaceous outcropping sites. The two camera systems used at each site were different models that operate differently: one was a Model TM 1500 active-infrared system and the other was a Model TM 500 passive infrared system. ${ }^{5}$ These trail monitors or "camera traps," as they are sometimes called, utilize automated cameras that are triggered either by the breaking of an infrared light beam (active systems) or by movement and body heat (passive systems). We set both types of systems so that cameras would be triggered by animal movement near small clusters of flowering Churchill Narrows buckwheat plants and focused the cameras on these plants. Cameras were left in place for two weeks (10-24 August 2007) before resulting photos were processed.

Our efforts resulted in only 10 animal photos among all four camera systems, but the story they suggested is truly an example of the timeless saying, "a picture is worth a thousand words." The active camera systems performed better than passive systems at both diatomaceous outcroppings. Both active systems produced four photos, consisting (in both cases) of two pictures of blacktail jackrabbits and two pictures of grey foxes (Urocyon cinereoargenteus). In three of the four jackrabbit photos, the subjects' heads are conspicuously placed into the flower stalks of a Churchill Narrows buckwheat plant (Fig. 2). At one of the sites, the obvious presence of a tick near the eye of one rabbit indicated that our two rabbit photos represented two different individuals. The passive camera systems produced only one animal photo at each of the two outcroppings: a grey fox at one site and a kangaroo rat at the other.

\section{Flower Counts}

Photographic evidence that removal of Churchill Narrows buckwheat flowers is attributable to herbivory by blacktail jackrabbits does not exonerate granivores from also playing a role in flower removal. Casual observations led us to believe that it was primarily developing white flowers that were being removed from plants rather than mature red flowers, so we decided to quantify removal of each type of flower. Reasoning that granivores would harvest flowers containing mature seeds while herbivores would prefer developing flowers (even though they may also consume
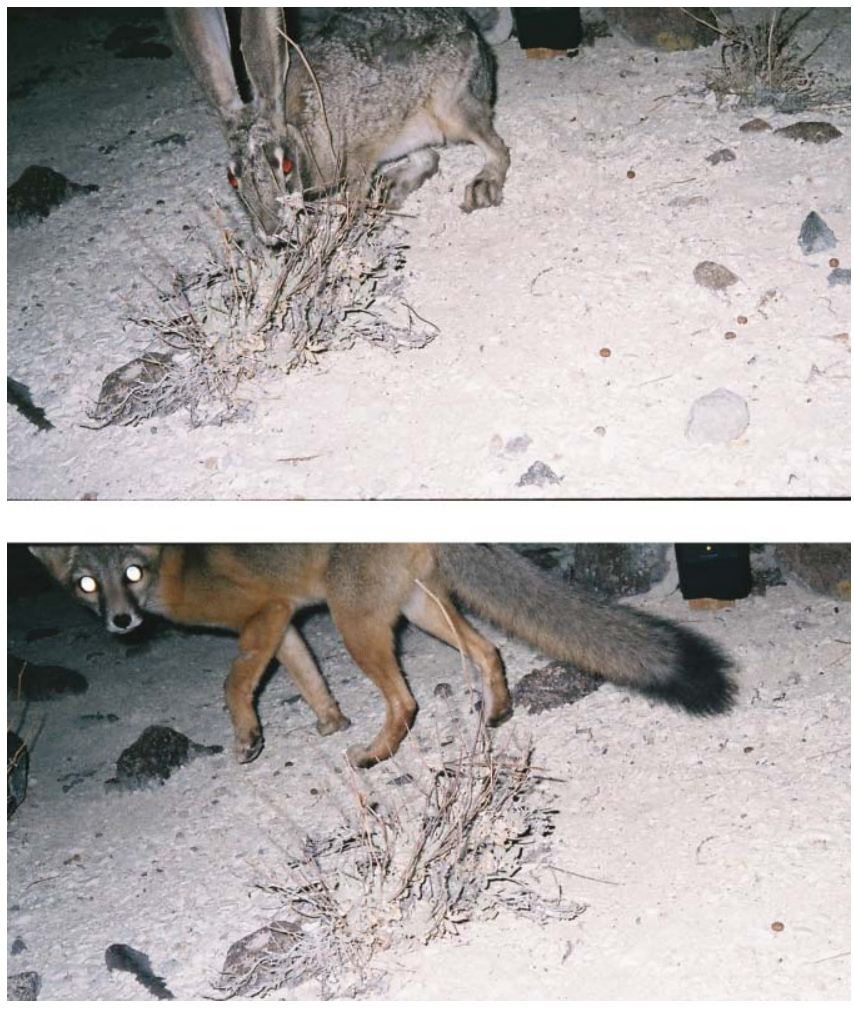

Figure 2. Wildlife camera trap photographs taken at the study sites of a blacktail jackrabbit (Lepus californus; top) feeding on Churchill Narrows buckwheat and a gray fox (Urocyon cinereoargenteus; bottom). Would jackrabbit herbivory on these plants be more extensive if not for the apparently frequent presence of foxes?

mature flowers), we monitored flower removal from seven Churchill Narrows buckwheat plants with developing flowers and five nearby plants with mature flowers between 24 July 2007 and 27 October 2007.

The numbers of flowers were similar on plants with developing flowers (mean number of flowers per plant $\pm \mathrm{SD}=13.4 \pm 1.5)$ and those with mature flowers $(14.6 \pm 3.2$ flowers per plant) when monitoring began (Fig. 3). Removal of developing flowers was gradual through our third sampling date (1 August 2007), but occurred much more rapidly over the next three sampling dates (through 24 August), after which it appeared to again occur more gradually for the remainder of the sampling period (Fig. 3). New flowers occasionally emerged over the sampling period on plants with developing flowers, but removal by animals was sufficiently frequent to prevent new flowers from increasing the flower count from one sampling date to the next. On the last day we counted flowers, the mean number of developing flowers had been reduced to just $0.7( \pm 1.3)$ per plant. By contrast, numbers of flowers on those plants with mature red flowers remained constant throughout the entire sampling period (Fig. 3). Not a single mature flower was removed during our counts, although some were slightly damaged, perhaps by wind, over the course of sampling. 

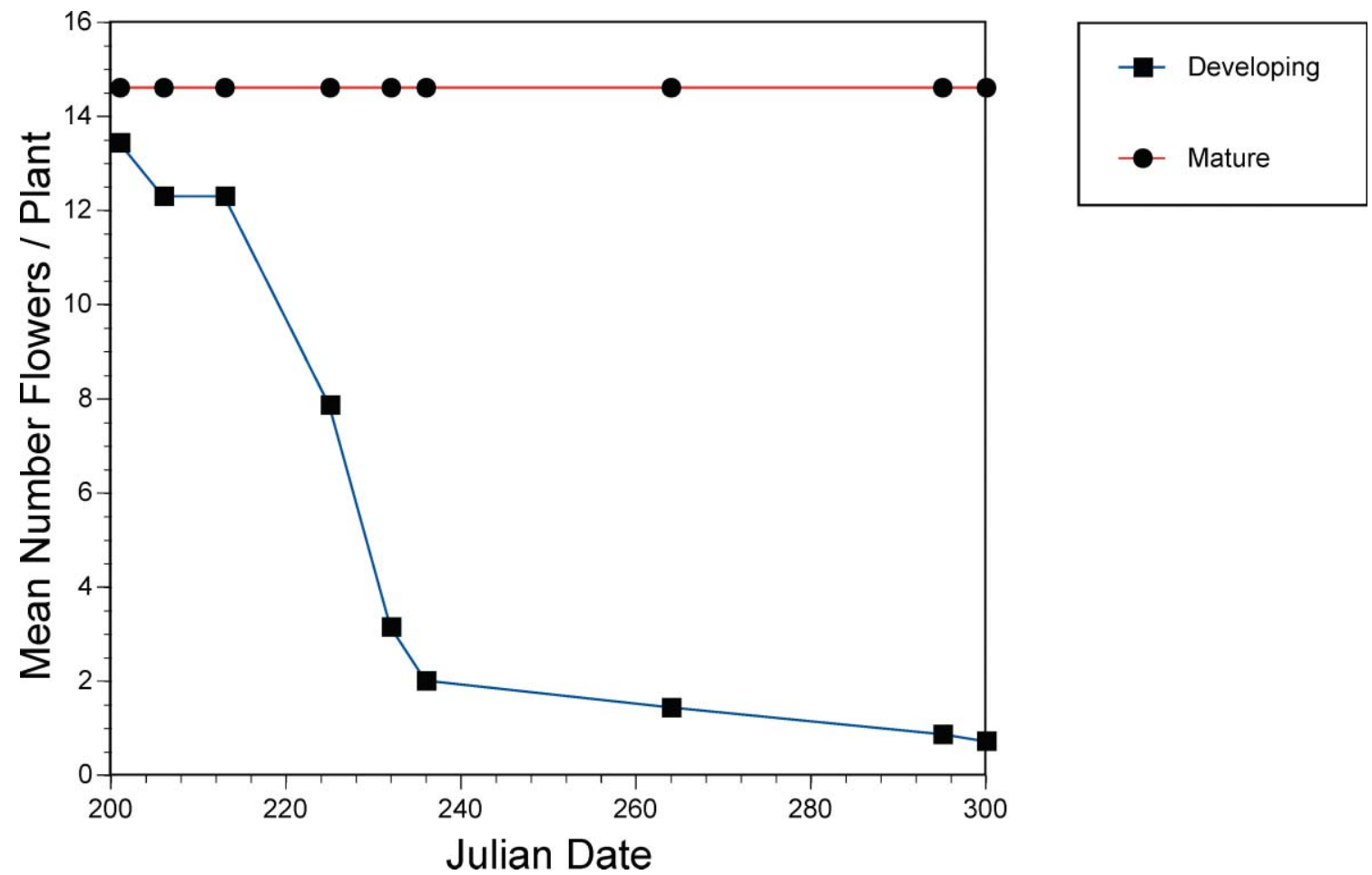

Figure 3. Number of developing and mature flowers per plant on focal Churchill Narrows buckwheat plants, 20 July-27 October 2007.

\section{Conclusions}

The fact that mature red flowers containing seeds were not clipped from the Churchill Narrows buckwheat plants we monitored suggests that granivorous rodents were not the agents of flower removal. This does not mean, however, that these animals do not harvest seeds of this plant when they are shed to the ground. Based on our rabbit pellet counts, tracking stations, and photos from camera trap systems, we conclude that herbivory by blacktail jackrabbits is the primary agent of buckwheat flower attrition at our Churchill Narrows sites. Although we might have expected to get photos of jackrabbits consuming buckwheat plants, we were surprised to find an equal number of grey fox photos from each of the active camera systems (Fig. 2). The diatomaceous outcroppings that comprise habitat for Churchill Narrows buckwheat may offer ideal hunting areas for carnivores: vegetation cover is noticeably more sparse than on surrounding volcanic soils, and prey animals probably stand out more against the background of the white diatomaceous soils than they would on a dark volcanic substrate. If foxes visit the diatomaceous soil sites frequently, as appears to be the case based on us obtaining slightly more fox (five) than jackrabbit (four) photos, it is likely that behavioral avoidance of predation reduces jackrabbit herbivory below the level that would occur in the absence of foxes. If not for the foxes, flower consumption might be even more severe.

Whether or not the jackrabbit herbivory on developing flowers limits seedling recruitment of Churchill Narrows buckwheat remains unresolved. In spite of the high level of flower herbivory we documented, a few plants still had a flower or two remaining at the end of our flower counts, and the rate of herbivory had slowed considerably by that time. Moreover, we were able to find some plants whose flowers had already matured when we started our work. These earlymaturing flowers persisted throughout the study period, implying that early flower production may be advantageous to Churchill Narrows buckwheat. Considering both the typically long time periods between bouts of seedling recruitment in many desert perennials and the extended periods of seed dormancy exhibited by such species, ${ }^{6}$ viable buckwheat seeds may persist in soil seed banks for many years. Therefore, even if seed production is extremely limited in any given year, seed banks may still gradually accumulate before conditions are appropriate to promote seedling establishment. The potential for reduced seed production to limit seed banks and subsequent seedling recruitment of Churchill Narrows buckwheat deserves further attention.

Churchill Narrows buckwheat has coexisted with jackrabbits for thousands of years. There is little doubt that the primary threat to the continued existence of this plant comes from potential development of a mining operation in the area for the mineral diatomite. ${ }^{1-3}$ Regardless of this, effective management for the protection of a rare plant still requires an understanding of the species' basic reproductive biology and ecological interactions impacting its reproduction. If further studies reveal a limiting effect of seed banks on seedling recruitment of Churchill Narrows buckwheat, active management to reduce jackrabbit herbivory (i.e., fencing off 
patches of plants or taking measures to augment predator populations) may become necessary to maintain populations of this plant, especially if it becomes federally listed.

\section{References}

1. Reynolds, J. 2001. Current knowledge and conservation status of Eriogonum diatomaceum Reveal, J. Reynolds, and Picciani (Polygonaceae: Eriogonoideae), Churchill Narrows buckwheat. Carson City, NV, USA: Status report prepared for US Department of the Interior, Bureau of Land Management, Nevada State Office and Nevada Natural Heritage Program, Department of Conservation and Natural Resources. 18 p.

2. Reveal, J. L., J. Reynolds, And J. Picciani. 2002. Erigiogonum diatomaceum (Polygonaceae: Eriogonoideae), a new species from western Nevada, USA. Novon 12:87-89.

3. US Fish and Wildlife Service. 2007. US Fish and Wildlife Service species assessment and listing priority assignment form for Eriogonum diatomaceum. Available at: http://ecos.fws.gov/ docs/candforms_pdf/r8/Q3IP_P01.pdf. Accessed 25 October 2007.

4. McAdoo, J. K., W. S. Longland, G. J. Cluff, and D. A. Klebenow. 1987. Use of new rangeland seedings by black-tailed jackrabbits. Journal of Range Management 40:520-524.
5. Hernandez, F., D. Rollins, and R. Cantu. 1997. An evaluation of Trailmaster ${ }^{\circledR}$ camera systems for identifying ground-nest predators. Wildlife Society Bulletin 25:848-853.

6. Chambers, J. C., and J. A. MacMahon. 1994. A day in the life of a seed: movements and fates of seeds and their implications for natural and managed systems. Annual Review of Ecology and Systematics 25:263-292.

Authors are Ecologist, USDA-Agricultural Research Service, Exotic and Invasive Weeds Research, 920 Valley Rd, Reno, NV 89512, USA, longland@unr.nevada.edu (Longland); BS student, Dept of Natural Resource and Environmental Sciences, University of Nevada, Reno, NV 89512, USA (Aten); MS student, Dept of Biology, University of Nevada, Reno, NV 89557, USA (Swartz); and Intern, Bureau of Land Management, Carson City Field Office, 5665 Morgan Mill Rd, Carson City, NV 89701, USA (Kulpa). Current address for Kulpa: Dept of Natural Resource and Environmental Sciences, University of Nevada, Reno, NV 89512, USA. This paper is a joint contribution of the USDA-Agricultural Research Service and the University of Nevada, Reno. 